\title{
Opportunistic Infections and Associated Factors among HIV/AIDS Patients taking Ante-Retroviral Therapy Leku, Bona and Yirgalem Hospitals in Sidama Zone, Southern Ethiopia.
}

Demelash Wachamo ( $\square$ demmenew1@gmail.com )

Hawassa College of Health Science

Fisseha Bonja

Hawassa University College of Medicine and Health Sciences

Research article

Keywords: Opportunistic infection, HIV/AIDS, WHO clinical stage, Hawassa, Ethiopia

Posted Date: December 31st, 2019

DOI: https://doi.org/10.21203/rs.2.17125/v2

License: (a) (1) This work is licensed under a Creative Commons Attribution 4.0 International License.

Read Full License 


\section{Abstract}

\section{Background}

Opportunistic infections are late complications of HIV infection is the depletion of the immune system. It is a major public health problem and high morbidity AIDS patients die of AIDS-related infections in developing countries like Ethiopia. Identification of opportunistic infections (Ols) is important to develop a specific intervention. Therefore, this study aimed to assess the burden and associated factors of opportunistic infections.

\section{Method}

A facility-based cross-sectional study was conducted on 420 randomly selected HIV/AIDS patients taking anti-retroviral therapy. Data was collected from selected hospitals in Sidama Zone based on population proportion to size. Data was collected by a pre-tested questionnaire and a pre-tested checklist from the medical records of patients. Data entry and analyzed for descriptive and logistic regression models by SPSS v.23. The result declared as statistically significant at $p<0.05$.

\section{Result}

The magnitude of opportunistic infections was $39.6 \%$. Major identified Ols was oral candidacies $23.2 \%$, recurrent bacterial pneumonia 21.5\%, Herpes zoster 6.3\%, and Pulmonary Tuberculosis $6.0 \%$.The magnitude of opportunistic associated with; older age [AOR=2.61, 95\% Cl: 1.30-5.23], No formal education [AOR=3.09, 95\% Cl: 1.11-8.60], monthly income below 1920 ETB [AOR=2.37, 95\% Cl: 1.43-3.94], initial CD4 count less than 200 cells/mm3 [AOR=2.30, 95\% Cl:1.06-4.98), had no extra medicine additional to ART (prophylaxis) had [AOR= 8.79, 95\% Cl: 5.05-15.30], who interrupt ART medicines [AOR=2.16, 95\% Cl: 1.19-3.91] and Khat chewing [AOR=5.52, 95\% Cl: 2.42-12.56] when compared to their counterparts.

\section{Conclusions}

The overall magnitude of opportunistic infections was high when compared with other studies. Health officials and clinicians need to give attention to the strengthening of the provision if ART with prophylaxis on early-stage and adherence, implementation of the TB/HIV collaboration activity, and early initiation of ART to reduce opportunistic infections.

\section{Background}

Human immune virus (HIV/ADIS), with which 36.7 million people were living and 2.1 million infected at the end of 2016, has been a major health problem throughout the world [1]. Around 36.7 million people worldwide are currently living with HIV, of which $52 \%$ reside in sub-Saharan Africa (SSA) [2]. It affected 1 in every 25 Adults (4.4\%) is living with the deadly virus, account for nearly $70 \%$ of the global burden of HIV $[3,4]$. Although the natural history of HIV inclines to be similar, the patterns of Ols that mainly 
presented with different clinical manifestation regions to the region $[5,6]$. CDC estimates that in 2015, $15 \%$ of the people with HIV in the United States were unaware or asymptomatic of their infections $[7,8]$. The commonly reported opportunistic diseases in sub-Saharan Africa among HIV patients are Candidiasis, Pneumocystis carinii pneumonia (PCP), disseminated Mycobacterium avium complex (MAC) infection, Cryptococcus, Kaposi sarcoma, herpes zoster, and tuberculosis $[9,10]$.

The developing countries more suffer from bacterial and protozoal infections due to lack of resources [11, 12], HIV diagnosis, poor adherence to Anti-Retroviral Treatment (ART), drug resistance, poverty, poor nutrition, and high exposure to infectious agents [13]. The opportunistic infections may favor HIV replication and higher viral loads that lead to lower the quality of life of HIV infected persons, reduces patients' response to ART, increases stigma and limit one's ability to work, high medical care costs, and death $[14,15]$.

In Ethiopia, the adult HIV prevalence of Ethiopia was estimated to be $1.1 \%$ in 2015, and the second leading cause of death [16]. More than $90 \%$ of HIV/AIDS deaths are attributable to opportunistic infections and malignancies [11]. Even though nationally representative and comprehensive data regarding the magnitude of opportunistic infections lack in Ethiopia, some regional studies have shown the prevalence ranging from $19.7 \%$ to $48 \%[15,17]$. The prevalence of Ols among HIV patients on ART is still high namely; oral candidiasis $11.8 \%$, followed by chronic diarrhea, $9.9 \%$ and tuberculosis $9.7 \%$ at Debre Markos referral hospital in Ethiopian [18]. Which associated with age, WHO stages of III and IV, chew khat, ART adherence, low level of hemoglobin, and recent weight [18]. Hence, it is very important to see the magnitude of opportunistic infections and its determinant factors to reduce the burden. This is important for researchers, clinicians, and health planners.

\section{Methods}

\section{Study setting and study population}

This study was conducted at Leku, Bona and Yirgalem Hospitals in the Sidama Zone in southern Ethiopia from February 01, 2019, up to May 01, 2019, which is one of the most densely populated areas in Ethiopia. Sidama Zone located about 275 kilometers away from Addis Ababa. Sidama has a variety of climatic conditions. Warm conditions cover $54 \%$ of the area. There are only three well-organized ART facilities at the hospital level. The source of populations were all HIV/AIDS patients who visited the ART clinic of the three hospitals in the Sidama zone. All HIV positive adults who had at least one month follow up on ART unit at selected hospitals within the study period was considered as the study population. All randomly selected HIV positive adults aged 18 years old and above and who can give informed consent were included in the study. While, All HIV-infected patients admitted to the intensive care unit, and seriously ill patients during the study period were excluded from the study.

\section{Sample size and sampling technique}


The study was conducted on 420 calculated by a single population proportion formula by taking previously conducted prevalence of opportunistic infections in Debre Markos Referral Hospital, Northwest Ethiopia [18] and 10\% possible non-response rate. The stratified sampling technique was used to recruit ART hospitals. The desired number of clients for each hospital was selected based on proportional sampling. Individual study participants were selected from each hospital were recruited by the random arrival of the ART unit.

\section{Data collection tools, and procedures}

Data was collected by face to face interviews by using a pre-tested questionnaire; a pre-tested checklist done to collect information regarding Ols and patients' clinical records were reviewed.A pre-tested structured questionnaire was utilized to collect socio-demographic characteristics, clinical information, and other risk factors. The questionnaires were pretested and validated before two weeks in the study time in Dore Bafana primary hospital on $5 \%$ of HIV positive patients who attend ART clinic which was outside of the study area and necessary modifications were done based on the findings. Data collectors were five clinical nurses supervised by one BSC nurse supervisor and investigators. Training and practical demonstrations on interview techniques and document extraction procedures based on the checklist were given to data collectors for two consecutive days assessed for competency.

\section{Data quality control measures}

Data collectors were trained and the questioners were pretested before the study time in similar settings which are not a part of the study area. After the data collection process, the data were checked for completeness and any incomplete or misfiled questionnaires filed again.

\section{Data Analysis}

Data entry, cleaning, and analysis were done by SPSS V. 23. Descriptive analysis including frequency distribution and the percentage was made to determine the magnitude of the opportunistic infections, to describe socio-demographic and clinical characteristics. All factors with p-value $<0.25$ in the bivariate logistic regression analysis were a candidate to the multivariable model to control confounding effects.

The Hosmer -Lemeshow goodness-of-fit statistic was used to assess whether the necessary assumptions for the application of multiple logistic regression are fulfilled. Odds ratios (OR) with $95 \%$ confidence intervals $(\mathrm{Cl})$ were calculated. Finally, p-value $<0.05$ declared a significant association.

\section{Terms and definitions}

- Opportunistic infection: If the study participant diagnosed at least one or more opportunistic infections; any infections of bacteria, viruses, fungi, Parasitic or protozoa or multiple infections 
reported on their medical record [7].

- Adverse effect: an unwanted effect caused by the administration of drugs. Onset may be sudden or developed over time.

- Current alcohol consumption: is defined as the use of alcohol at least once during the past 30 days before the survey.

- Khat chewing: is defined as the study participants who had chewed the leaves of Khat (Catha edulis) in the last 30 days.

- Cigarette smokers: is defined as individuals who had used smoke cigarettes form of tobacco in the last 30 days [19].

\section{Results}

A total of $420 \mathrm{HIV}$ positive adults were enrolled in the study in the ART clinic of the selected three hospitals, 414 participants were interviewed yielding a response rate of $98.57 \%$. The average age of the participants aged $18-55$ years, with the mean $( \pm S D)$ age of $30.69( \pm 7.350)$. More than half of the studied participants $234(56.5 \%)$ were female and $171(41.3 \%)$ in the age category of 25 - 34 years old. The majority of 259 (62.6\%) were married and 264(63.8\%) were living with their families. Regarding educational status, 25 (6.0\%) have no formal education, $102(24.6 \%)$ had a primary school, and 287 $(69.3 \%)$ had high school and above education. The working status of the participants $278(67.1 \%)$ was actively working. The monthly income of the households, 223 (53.9\%) earned between 300 - 1920 ETB, and 191 (46.1\%) earned more than 1920 ETB (Table 1).

\section{Environmental and Behavioral related characteristics}

The majority of $273(65.9 \%)$ were living in the cemented floor house. Most of 401 (96.9\%) had a latrine, among this 395 (95.4\%) were shared with their family and neighbors. More than half of $287(69.8 \%)$ used Garbage can or sac to disposer refuse. The main source of drinking water was 398 (96.1\%) pipe water. Regarding behavioral related factors, 27 (6.5\%) were used any tobacco products, among this $14(3.4 \%)$ were current cigarette smokers. The prevalence of Khat chewing was 48 (11.6\%). Regarding alcohol consumption, 71 (17.1\%) were ever drunk alcohol, 63 (15.2\%) were drinking alcohol in the last 30 days (Table 2).

\section{Health care system and Clinical Setting related factors}

However, more than half of the participants $263(63.5 \%)$ had doubts about health care providers. The majority of $376(90.8 \%)$ knew the importance of adherence to ART. Mainly, 352 (85.0\%) were believe that using ART improves life and lives longer, 408 (98.6) were agree that ART can prevent Ols and AIDS (S1). 


\section{Patient health condition related factors}

Eighty-three (20.0\%) of the study participants had a history of side effects on ART drugs and 202 (48.8\%) were taken extra drugs additional to ART drugs (S1). Nearly half of, $206(49.8 \%)$ were on WHO clinical stage I, while $83(20.0 \%)$ and 31 (7.5\%) were on WHO clinical stage III and IV, respectively (Fig. 1).

\section{The magnitude of Opportunistic Infections}

The overall magnitude of opportunistic infections was 39.6\%, [95\% Cl: 35.0 - 44.4] were found to be infected by one or more opportunistic infections among HIV/AIDS Patients taking ART at Selected Hospitals in Sidama Zone, Southern Ethiopia. Major identified opportunistic infections were oral candidacies 96 (23.2\%), recurrent bacterial pneumonia 89 (21.5\%), Herpes zoster 26 (6.3\%), Pulmonary Tuberculosis 25 (6.0\%), Extrapulmonary TB. 24 (5.8\%), and Crypto-coca meningitis 9 (2.2\%) (Fig. 2).

\section{Associated Factors for Opportunistic Infections}

In the multivariate analysis age of respondents, household monthly income, initial CD4 count, education, had no extra medicine additional to ART (prophylaxis), taking ART medicines properly, and Khat chewing remained as the determinant of opportunistic infections. This study result shows that advancing in the age had about 2.6 times more exposed to develop Ols [AOR $=2.61,95 \% \mathrm{Cl}: 1.30-5.23$ ], as compared with younger age. No formal education had $[\mathrm{AOR}=3.09,95 \% \mathrm{Cl}: 1.11-8.60]$, Household monthly income below 1920 ETB had [AOR $=2.37,95 \% \mathrm{Cl}: 1.43-3.94]$, had more exposed to Ols as to their counterparts. Initial CD 4 count less than 200 cells $/ \mathrm{mm}^{3}$ had [AOR $\left.=2.30,95 \% \mathrm{Cl}: 1.06-4.98\right]$, The study participants who had no extra medicine additional to ART (prophylaxis) [AOR $=8.79,95 \% \mathrm{Cl}$ : 5.05-15.30], interrupt ART medicines had [AOR $=2.16,95 \% \mathrm{Cl}: 1.19-3.91]$ and Khat chewing [AOR $=5.52,95 \% \mathrm{Cl}: 2.42-12.56]$ were more exposed to Ols when compared to their counterparts (Table 3 ).

\section{Discussions}

This facility-based cross-sectional study revealed that the magnitude of opportunistic infections was $39.6 \%$, [95\% Cl: 35.0 - 44.4] were found to be infected by one or more opportunistic infections among HIV/AIDS Patients taking ART at Selected Hospitals in Sidama Zone, Southern Ethiopia. Major identified opportunistic infections were Oral candidacies $23.2 \%$, recurrent bacterial pneumonia $21.5 \%$, Herpes zoster $6.3 \%$, and Pulmonary Tuberculosis $6.0 \%$. This study result was consistent with the study findings in Wolaita Zone, Southern Ethiopia 45.3\% [11] and Uganda 43\% [9]. This result higher when compared to eastern Ethiopia 20.2\% had any form of tuberculosis, oral candidiasis, herpes zoster [15], 22.4\% Nigeria [20], 19.7\% Northern Ethiopia [21]. While, it was slightly lower when compared with 61.7\% Nigeria [22], 47.6\% Taiwan [23], and 48\% eastern Ethiopia [15]. The discrepancy might be due to differences in geographical areas of study participants, high exposure to infectious agents, social-economic status, drug resistance, immunity and nutrition, may affect the magnitude of Ols. 
This study result revealed that advancing in the age was more exposes to Ols as compared with younger age. Similar to the United States [24], and Northwest Ethiopia [25]. The possible reason maybe, when they grow older the patients' immune get decreased due to the increased number of viral load and other factors predispose to Ols. In addition to that, the study participants who had no formal education exposes to Ols more when compared with high and above education. This finding was also similar to Debre Markos Referral Hospital, Northwest Ethiopia [25], and eastern Ethiopia [15]. This may due to a lack of health-related information about prevention, early symptoms and health benefits. Low household monthly income was more exposed to Ols than to their counterparts. This finding is consistent with Bangladesh [26], and the Lao People's Democratic Republic (PDR) [27]. This might due to household income directly related to the nutritional status and sanitation status of the individuals.

Initial CD4 count less than 200 cells/mm3 was more exposed to Ols as compared with higher CD4 count. This study finding agrees with eastern Ethiopia [15], and the Amhara region, Ethiopia [28]. This might due to the low body defense mechanism favored the Ols. The study participants who interrupt ART medicines and who had no extra medicine additional to ART (prophylaxis) had high odds of to develop Ols. This study finding consistent with eastern Ethiopia [15], and Dessie hospital ART clinic, Northeast Ethiopia [29]. This might due to Ols could be prevented by using extra drugs additional to ART drugs or prophylaxis.

This study result showed that Khat chewing was more exposed to Ols. Similarly reported in Northwest Ethiopia [25], and eastern Ethiopia [15]. The possible reason may be, chewing Khat causes malnutrition due to poor appetite and it affects health-seeking behavior by temporary relief.

This study result shows there was a high prevalence of Ols. This may due to there is an endemic intestinal parasite in the area which exposes the patient to daily activities or this could be a sign of resistance/ treatment failure that needs to be further investigated. Which related to occurred irrespective of the income status, chewing Khat, interrupt ART medicines and who had no extra medicine additional to ART (prophylaxis), low educational status and due to poor level of health-seeking behavior of the study participants. These study findings recommend for more consideration on different strategies to address early detection for better prevention, evaluation, and management. Future research should explore more by triangulating with qualitative study for factors with Ols to design targeted interventions.

This study has potential limitations as the study is cross-sectional in design; it neither represents the seasonal variation of nutritional outcomes nor establishes a causal relationship. In addition to this, the odds ratios of the cross-sectional study did not show the strength of an association.

\section{Conclusions}

This study result shows there was a high prevalence of opportunistic infection among HIV/AIDS patients taking anti-retroviral therapy. This indicates that the threatening burden of opportunistic infections couldn't be averted by only the provision of anti-retroviral therapy. The most common opportunistic infections were of oral candidiasis, herpes zoster, and tuberculosis (pulmonary and extrapulmonary). 
Older age of respondent, household monthly income, initial CD4 count, advancing WHO clinical staging, had no formal education, had no extra medicine additional to ART (prophylaxis), participants who interrupt ART medicines, and Khat chewing were found determinant factors for opportunistic infections when compared to their counterparts.

\section{Declarations}

\section{Abbreviations}

ART = Ante-retroviral therapy, $C D 4=$ Cell with $C D-4$ marker, ETB $=$ Ethiopian birr, Ols $=$ Opportunistic infections, SPSS = Statistical Package for Social Science, STD = Sexually transmitted disease, TB = Tuberculosis, $\mathrm{WHO}=$ World Health Organization

\section{Ethics approval and consent to participate}

Ethical clearance was obtained from Hawassa university college of medicine and health sciences ethical review committee, support letter was also requested from the Sidama zone health bureau. All participants informed well about purpose, risk and benefit, and confidentiality. Participation was fully voluntary and written informed consent (verbal consent for who cannot read and write respondent) was obtained from each participant. The patients' medical records were reviewed anonymously, and all information obtained from medical records was kept confidential.

\section{Consent for publication}

Not applicable.

\section{Availability of data and materials}

There is no remaining data and materials, all information is clearly presented in the main manuscript.

\section{Competing interests}

The authors declare that they have no conflict of interests.

\section{Funding}

No funding was obtained. 


\section{Authors' contributions}

DW wrote the proposal, participated in data collection, analyzed the data and drafted the paper and manuscript writing. FB approved the proposal with some revisions, participated in data collection, analysis. authors read and approved the final manuscript.

\section{Acknowledgments}

The authors would like to thank Hawassa University, College of Medicine and Health Science for ethical approval. We would like to thanks to Sidama zone health bureau for their cooperation on providing, information and support letter. The authors are also grateful to all data collectors and study participants for their valuable contributions.

\section{References}

1. Coleman R L, McLean S. Commentary: the value of PrEP for people who inject drugs. Journal of the International AIDS Society. 2016;19:21112.

2. CampBinford M, Kahana S Y, Altice F L. A Systematic Review of Antiretroviral Adherence Interventions for HIV-Infected People Who Use Drugs. Current HIV/AIDS reports. 2012;9(4):287-312.

3. Csete J, Kamarulzaman A, Kazatchkine M, Altice F, Balicki M, et al. Public health and international drug policy. Lancet (London, England). 2016;387(10026):1427-80.

4. Heestermans T, Browne J L, Aitken S C, Vervoort S C, Klipstein-Grobusch K. Determinants of adherence to antiretroviral therapy among HIV-positive adults in sub-Saharan Africa: a systematic review. BMJ Global Health. 2016;1(4):e000125.

5. Pantoja T, Opiyo N, Lewin S, Paulsen E, Ciapponi A, et al. Implementation strategies for health systems in low-income countries: an overview of systematic reviews. The Cochrane Database of Systematic Reviews. 2017;10.1002/14651858.CD011086.pub2(9):CD011086.

6. lacob S A, lacob D G, Jugulete G. Improving the Adherence to Antiretroviral Therapy, a Difficult but Essential Task for a Successful HIV Treatment-Clinical Points of View and Practical Considerations. Frontiers in Pharmacology. 2017;8:831.

7. Panel on Opportunistic Infections in Adults and Adolescents with HIV. Guidelines for the prevention and treatment of opportunistic infections in adults and adolescents with HIV: recommendations from the Centers for Disease Control and Prevention, the National Institutes of Health, and the HIV Medicine Association of the Infectious Diseases Society of America.:AIDSinfo; 2019. p. 1-5.

8. UNAIDS. Global AIDS update 2016. Geneva. WHO/UNAIDS. 2016.

9. Rubaihayo J, Tumwesigye N M, Konde-Lule J. Trends in prevalence of selected opportunistic infections associated with HIV/AIDS in Uganda. BMC Infectious Diseases. 2015;15:187. 
10. Hakim J, Maitland K. Oral abstracts of the 21st International AIDS Conference 18-22 July 2016, Durban, South Africa. 2016.

11. Alemayehu M, Yisehak Y, Alaro W, Alemayehu B. Opportunistic Infections among HIV/AIDS Patients taking Ante-Retroviral Therapy at Tertiary Care Hospital in Wolaita Zone, Southern Ethiopia. J AIDS Clin Res 2017;8:665.

12. Oral abstracts of the 21 st International AIDS Conference. Journal of the International AIDS Society. 2017;20(Suppl 5):22253.

13. Rubaihayo J, Tumwesigye N M, Konde-Lule J, Wamani H, Nakku-Joloba E, et al. Frequency and distribution patterns of opportunistic infections associated with HIV/AIDS in Uganda. BMC Research Notes. 2016;9:501.

14. Jaillette E, Girault C, Brunin G, Zerimech F, Chiche A, et al. French Intensive Care Society, International congress-Réanimation 2016. Annals of Intensive Care. 2016;6(Suppl 1):50.

15. Mitiku H, Weldegebreal F, Teklemariam Z. Magnitude of opportunistic infections and associated factors in HIV-infected adults on antiretroviral therapy in eastern Ethiopia. HIV/AIDS (Auckland, NZ). 2015;7:137-44.

16. WHO. HIV/AIDS facts sheet. Geneva. WHO. 2015.

17. Kindie E, Alamrew Anteneh Z, Worku E. Time to development of adverse drug reactions and associated factors among adult HIV positive patients on antiretroviral treatment in Bahir Dar City, Northwest Ethiopia. PLOS ONE. 2017;12(12):e0189322.

18. Moges NA, Kassa GM. Prevalence of opportunistic infections and associated factors among HIV positive patients taking antiretroviral therapy in Debremarkos referral hospital, Northwest Ethiopia. J AIDS Clin Res 2014;5:301.

19. World Health Organization W. Chronic diseases and health promotion. STEP wise approach to chronic disease risk factor surveillance (STEPS).. Geneva:World Health Organization. 2010.

20. Iroezindu M, Ofondu E, Hausler H, Van Wyk B. Prevalence and risk factors for opportunistic infections in HIV patients receiving antiretroviral therapy in a resource-limited setting in Nigeria. J AIDS Clin Res. 2013;3:002.

21. Damtie D, Yismaw G, Woldeyohannes D, Anagaw B. Common opportunistic infections and their CD4 cell correlates among HIV-infected patients attending at antiretroviral therapy clinic of Gondar University Hospital, Northwest Ethiopia.. BMC Res Notes 2013;6:534.

22. Iroezindu MO, Ofondu EO, HauslerH, B V. Prevalence and risk factors for opportunistic infections in hiv patients receiving antiretroviral therapy in a resource-limited setting in Nigeria.. J AIDS Clinic Res S. 2013:3: 002.

23. Sun HY, Chen MY, Hsieh SM. Changes in the clinical spectrum of opportunistic illnesses in persons with HIV infection in Taiwan in the era of highly active antiretroviral therapy. Jpn J Infect Dis 2006;59:311-6.

24. Mackellar D A, Valleroy L A, Secura G M, Behel S, Bingham T, et al. Unrecognized HIV infection, risk behaviors, and perceptions of risk among young men who have sex with men: opportunities for 
advancing HIV prevention in the third decade of HIV/AIDS. JAIDS Journal of Acquired Immune Deficiency Syndromes. 2005;38(5):603-14.

25. Moges N, Kassa G. Prevalence of Opportunistic Infections and Associated Factors among HIV Positive Patients taking Anti-Retroviral Therapy in DebreMarkos Referral Hospital, Northwest Ethiopia. Journal of AIDS \& Clinical Research. 2014;05.

26. Peltzer K, Pengpid S. Socioeconomic Factors in Adherence to HIV Therapy in Low- and Middleincome Countries. Journal of Health, Population, and Nutrition. 2013;31(2):150-70.

27. Hansana V, Sanchaisuriya P, Durham J, Sychareun V, Chaleunvong K, et al. Adherence to Antiretroviral Therapy (ART) among People Living With HIV (PLHIV): a cross-sectional survey to measure in Lao PDR. BMC Public Health. 2013;13:617-.

28. Mitku A A, Dessie Z G, Muluneh E K, Workie D L. Prevalence and associated factors of TB/HIV coinfection among HIV Infected patients in Amhara region, Ethiopia. African Health Sciences. 2016;16(2):588-95.

29. Missaye A, Dagnew M, Alemu A, Alemu A. Prevalence of intestinal parasites and associated risk factors among HIV/AIDS patients with pre-ART and on-ART attending Dessie hospital ART clinic, Northeast Ethiopia. AIDS Research and Therapy. 2013;10:7-.

\section{Tables}

Table 1: Socio-demographic characteristics of the study participants among HIV/AIDS Patients taking ART at Selected Hospitals in Sidama Zone, Southern Ethiopia, 2019. 


\begin{tabular}{lrl}
\hline Category & \multicolumn{1}{c}{ No. (\%) } \\
\hline Age of Respondents & \\
18 -24 years & $89(21.5)$ \\
25 - 34 years & $171(41.3)$ \\
35 or above years & $154(37.2)$ \\
Sex of respondents & \\
Male & $180(43.5)$ \\
Female & $234(56.5)$ \\
Marital status & \\
Married & $259(62.6)$ \\
Unmarried & $54(13.0)$ \\
Divorced & $50(12.1)$ \\
Separated & $14(3.4)$ \\
Widowed & $37(8.9)$ \\
Education status & \\
No formal education & $25(6.0)$ \\
Elementary School & $102(24.6)$ \\
High School & $254(61.4)$ \\
Diploma and Above & $33(8.0)$ \\
Working situation & \\
Working actively & $278(67.1)$ \\
Unemployed & $121(29.2)$ \\
Pensioner & $15(3.6)$ \\
Live with & \\
My family & $264(63.8)$ \\
Live alone & $77(18.6)$ \\
My parents & $54(13.0)$ \\
Unstable & $16(3.9)$ \\
No answer & $3(0.7)$ \\
Household income in Ethiopian Birr \\
300 - 1920 & $223(53.9)$ \\
$>$ 1920 & $191(46.1)$ \\
\hline &
\end{tabular}

NB: Working actively (government, NGO, Private and self employed), Income: based on (HCE, 2016) Exchange rate 1 USD to 29.3673ETB

Table 2: Environmental and Behavioral related characteristics among HIV/AIDS Patients taking ART at Selected Hospitals in Sidama Zone, Southern Ethiopia, 2019. 


\begin{tabular}{|c|c|}
\hline Variable Category & No. (\%) \\
\hline \multicolumn{2}{|l|}{ Floor of living house } \\
\hline Mud & $89(21.5)$ \\
\hline Cement & $273(65.9)$ \\
\hline Wood & $40(9.7)$ \\
\hline Others & $12(2.9)$ \\
\hline \multicolumn{2}{|l|}{ Latrine available } \\
\hline Yes & $401(96.9)$ \\
\hline No & $13(3.1)$ \\
\hline \multicolumn{2}{|l|}{ Ownership of the latrine } \\
\hline Private Owned & $19(4.6)$ \\
\hline Shared with neighbor & $395(95.4)$ \\
\hline \multicolumn{2}{|l|}{ Source of water for drink } \\
\hline Pipe & $398(96.1)$ \\
\hline Others & $12(4.9)$ \\
\hline \multicolumn{2}{|c|}{ Living with domestic animals and pets } \\
\hline Yes & $108(26.1)$ \\
\hline No & $306(73.9)$ \\
\hline \multicolumn{2}{|l|}{ Use any tobacco products } \\
\hline Yes & $27(6.5)$ \\
\hline No & $387(93.5)$ \\
\hline \multicolumn{2}{|l|}{ Smoke cigarettes in last 30 days } \\
\hline Yes & $14(3.4)$ \\
\hline Never & $400(96.6)$ \\
\hline \multicolumn{2}{|l|}{ Ever drunk alcohol } \\
\hline Yes & $71(17.1)$ \\
\hline No & $343(82.9)$ \\
\hline \multicolumn{2}{|l|}{ Currently drinking } \\
\hline Yes & $63(15.2)$ \\
\hline No & $351(84.8)$ \\
\hline \multicolumn{2}{|l|}{ Khat chewing } \\
\hline Yes & $48(11.6)$ \\
\hline No & $366(88.4)$ \\
\hline
\end{tabular}

Table 3: Bivariable and multivariable logistic regression analysis for opportunistic infections among on ART patients at selected hospitals in Sidama Zone, Southern Ethiopia, 2019. 


\section{Opportunistic infection}

Yes No

No. (\%) No. (\%) $\quad \operatorname{COR}(95 \% \mathrm{Cl}) \quad$ AOR $(95 \% \mathrm{Cl}) \quad$ P-Value

Age

$18-24$ years

$20(22.5) \quad 69(77.5)$

1

1

25 - 34 years

66 (38.6) 105 (61.4) 2.17(1.21, 3.89) 1.45(0.73, 2.99) 0.286

35 or above years

78 (50.6) $76(49.4) 3.54(1.96,6.39)$ 2.61(1.30, 5.23) $0.007 *$

Education status of respondents

No formal education $15(60.0) 10(40.0)$ 2.76(1.20,6.37) $3.09(1.11,8.60) \quad 0.031$ *

$\begin{array}{lllllll}\text { Elementary School } \quad 48(47.1) & 54(52.9) & 1.64(1.04,2.59) & 1.20(0.69,2.09) & 0.522\end{array}$

High School and Above 101 (35.2) $186(64.8) \quad 1 \quad 1$

Average monthly income

$<1920$ ETB

1920 and above

Initial CD4 count

$<200$ cells $/ \mathrm{mm} 3$

$\geq 200$ cells $/ \mathrm{mm} 3$
$107(48.0) 116(52.0) 2.17(1.44,3.26) 2.37(1.43,3.94) \quad 0.001 *$

$57(29.8) 134(70.2)$
1

Take extra medicine additional to ART (prophylaxis)

$\begin{array}{lrrrc}\text { Yes } & 25(13.8) & 156(86.2) & 1 & 1 \\ \text { No } & 139(59.7) & 94(40.3) & 9.23(5.62,15.16) 8.79(5.05,15.30)<0.001^{*}\end{array}$

Taking ART medicines properly

\begin{tabular}{|c|c|c|c|c|}
\hline Yes & 115 (34.5) $218(65.5)$ & 1 & 1 & \\
\hline No & $49(60.5) \quad 32(39.5)$ & $2.90(1.76,4.78)$ & $2.16(1.19,3.91)$ & $0.011^{*}$ \\
\hline
\end{tabular}

Smoke cigarettes in last 30 days

No

155 (38.8) 245 (61.3)

1

1

Yes

$9(64.3)$

5 (35.7)

$2.85(0.94,8.65)$

$1.08(0.22,5.27) \quad 0.926$

Khat chewing

No

131 (36.0) 233 (64.0)

1

1

Yes

$33(66.0) 17(34.0) 3.45(1.85,6.44) 5.52(2.42,12.56)<0.001 *$

NB: * statistically significant on multivariate analysis p-value (<0.05), COR: crude odds ratio, AOR: adjusted odds ratio, Cl: confidence interval, 1: reference.

Figures 


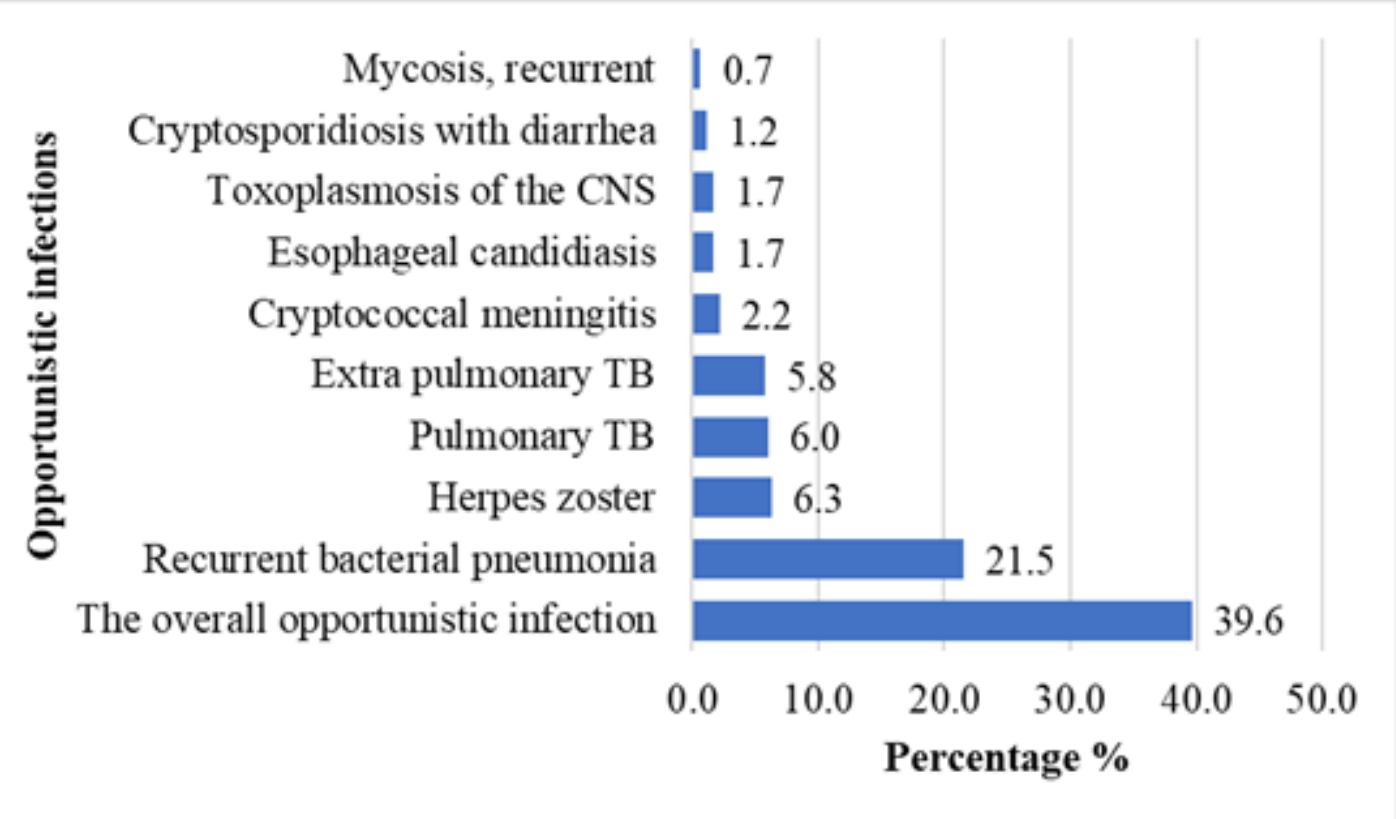

\section{Figure 1}

Magnitude of opportunistic infections among HIV/AIDS on ART at Selected Hospitals in Sidama Zone, Southern Ethiopia $2019(n=414)$.

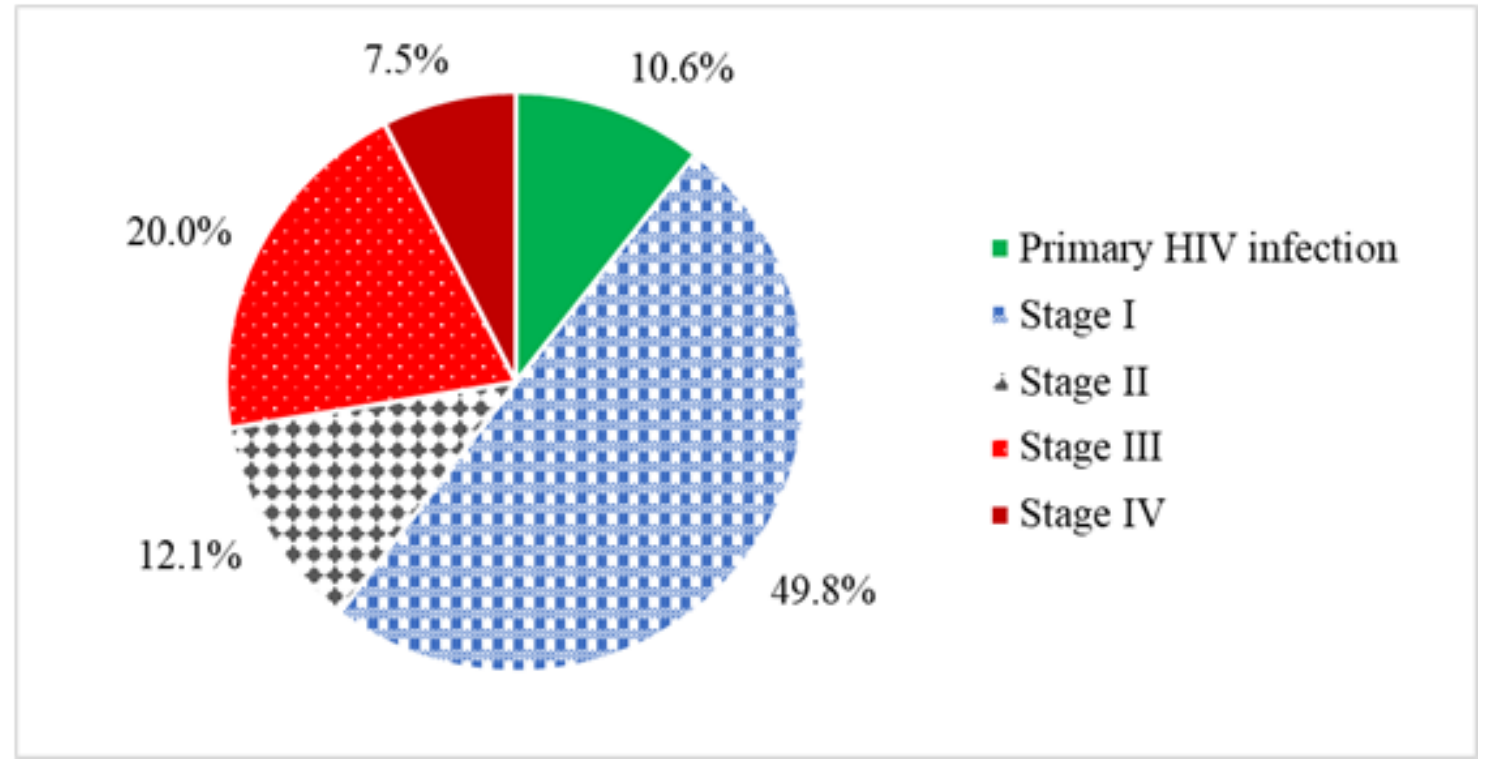

Figure 2

WHO clinical staging among HIV/AIDS on ART at Selected Hospitals in Sidama Zone, Southern Ethiopia $2019(n=414)$.

\section{Supplementary Files}

This is a list of supplementary files associated with this preprint. Click to download. 
- Supplementarymaterials.rar

Page 16/16 